\title{
Physio-morphological appraisal of aromatic fine rice (Oryza sativa L.) in relation to yield potential
}

\begin{abstract}
A field experiment was conducted to determine the physio-morphological attributes in relation to yield potential of modern and aromatic rice varieties. The experiment was laid out in a randomized complete block design (RCBD) with five replications. The results indicated that physio-morphological attributes, yield and yield contributing characters were varied among the varieties. The modern rice varieties BRRIdhan32 and Binasail showed larger grains, rice yield, biomass production and harvest index as compared to aromatic fine rice varieties. On the other hand, aromatic rice varieties showed tallest plant stature, profuse tillers hill-1, panicle hill-1 and larger panicle but smaller grain, higher grain yield, lowest straw yield and harvest index. Modern rice varieties generally had higher Total Dry Matter (TDM), Leaf Area Index (LAI), Leaf Area Ratio (LAR), Crop Growth Rate (CGR), Relative Growth Rate (RGR) whereas aromatic varieties resulted in higher Net Assimilation Rate (NAR). The results concluded that the modern rice varieties were more efficient in transfer of photosynthate to economic sink. The highest grain yield of modern rice varieties was due to the higher harvest index. Poor yield in aromatic rice varieties was due to lower translocation of assimilates. However, they have some characters viz., weak culms, drooping leaves, lodging which influence low yield. The results suggested that breeding programme may be undertaken to eliminate those defective characters for developing improved aromatic rice varieties.
\end{abstract}

Keyword: Aromatic; Modern rice; Physio-morphology; Yield; Rice 